\title{
miR-155 is up-regulated in primary and secondary glioblastoma and promotes tumour growth by inhibiting GABA receptors
}

\author{
PIETRO I. D'URSO ${ }^{1 *}$, OSCAR F. D'URSO ${ }^{1 *}$, CARLO STORELLI $^{1}$, \\ MASSIMO MALLARDO ${ }^{2}$, COSIMO DAMIANO GIANFREDA ${ }^{3}$, ANTONIO MONTINARO ${ }^{3}$, \\ ANTONIA CIMMINO $^{4}$, CALIANDRO PIETRO ${ }^{5,6}$ and SANTO MARSIGLIANTE ${ }^{1}$
}

${ }^{1}$ Department of Biological and Environmental Sciences and Technologies (DISTEBA), University of Salento, I-73100 Lecce; ${ }^{2}$ Department of Biochemistry and Medical Biotechnologies, University of Naples Federico II, I-80131 Naples; ${ }^{3}$ Neurosurgery Operative Unit, 'V. Fazzi' Hospital, I-73100 Lecce; ${ }^{4}$ Department of Pathology, University of Bari Medical School, I-70124 Bari; ${ }^{5}$ Catholic University of Sacred Heart, Policlinico A. Gemelli, Rome; ${ }^{6}$ Don Carlo Gnocchi Foundation, Rome, Italy

Received November 21, 2011; Accepted February 3, 2012

DOI: $10.3892 /$ ijo.2012.1420

\begin{abstract}
An altered expression of microRNAs (miRNAs) contributes both to the development of cancer and to the progression of the disease. Malignant tumours and tumour cell lines have widespread deregulated expressions of miRNAs compared to normal tissues. In this study, we investigated the expression profiles of 340 mammalian miRNAs in 93 cases of multiform glioblastoma (primary and secondary glioblastoma tumours), by means of DNA microarrays. We show that the expression profiles of 10 miRNAs can distinguish primary from secondary glioblastoma types. Moreover, we found elevated miR-155 levels in primary and secondary glioblastoma tissues as well as in glioblastoma primary cultures. We hypothesised that $\gamma$-aminobutyric acid A receptor 1 (GABRA1) is a miR-155 target, and studied the correlation between miR-155 up-regulation and the GABRA1 protein in cultured glioblastoma cells by miRNA silencing. We show that a decrease in miR-155 expression to normal levels restores the expression of GABRA1, making glioblastoma cells sensitive to signals that inhibit cell proliferation mediated by GABRA1. In conclusion, the expression patterns of different miRNAs characterise primary and secondary glioblastomas. The aberrant overexpression of miR-155 contributes to the malignant phenotype of glioblastoma cells removing growth inhibition.
\end{abstract}

Correspondence to: Professor Santo Marsigliante, Department of Biological and Environmental Sciences and Technologies (DISTEBA), University of Salento, Via Provinciale Lecce-Monteroni, I-73100 Lecce, Italy

E-mail: santo.marsigliante@unisalento.it

${ }^{*}$ Contributed equally

Key words: gene expression, microarray, microRNA, survival, glioblastoma

\section{Introduction}

microRNAs (miRNAs) are small (21-25 nucleotides in length) non-coding RNA molecules that negatively regulate protein expression by targeting the mRNA of protein-coding genes for either cleavage or repression of translation. They are involved in fundamental cellular processes such as brain development and neuronal differentiation (1-3). During brain development and neuronal differentiation, miRNAs are transcriptionally regulated and show a temporal wave of expression (4). By studying miRNA expression profiles in several cancer types and their activity on tumour suppressor genes or oncogenes, it was found that miRNAs are linked to cancer development (5-11). miR-155 is one of the miRNAs most frequently implicated in cancers. Transgenic mouse studies have demonstrated that B-cell-targeted expression of miR-155 leads to the development of B-cell malignancies (12). A number of miRNA profiling studies have shown elevated levels of miR-155 in a wide array of cancers, including lymphomas (12-16). Furthermore, it has been shown that a high expression of miR-155 in lung cancer correlates with poor survival rates (17). In glioblastoma multiforme (GBM) an increased expression of miR-21 with anti-apoptotic functions has been found (18). Huse et al reported the identification of miR-26a as a direct regulator of phosphatase and tensin homologue (PTEN) expression in highgrade glioma (19).

Glioblastomas represent $12-15 \%$ of intracranial tumours and $60-75 \%$ of astrocytic tumours. According to the current WHO classification of brain tumours glioblstoma is a grade IV astrocytoma. Glioblastomas can develop along two distinct clinical pathways: primary glioblastomas with no pathological precursor lesion, which have clinical prodromes of $<3$ months and secondary glioblastomas which may develop through progression from diffuse astrocytoma (WHO grade II) or anaplastic astrocytoma (WHO grade III). Secondary glioblastomas are less frequent than primary glioblastomas and typically develop in younger patients (mean age, 45 years). The time taken to progress from diffuse astrocytoma to GBM varies 
considerably, with intervals ranging from $<1$ year to $>10$ years (mean interval, 4-5 years) (20). After the molecular analysis of glioblastoma tissues, the amplification of the epidermal growth factor receptor (EGFR) has been identified as a genetic marker for primary glioblastoma. TP53 has also been identified as a marker for low-grade astrocytoma and secondary glioblastoma. Different transcriptional profiles reflect biological differences between primary and secondary glioblastomas (21). At the same time, the strikingly similar phenotype of glioblastomas is reflected in common genetic lesions, such as loss of PTEN and cyclin-dependent kinase (CDK) inhibitor 2A (CDKN2A), as well as amplification/overexpression of CDK4 and murine double minute 2 (MDM2) (22).

The purpose of this study was to find a 'molecular signature' in order to distinguish primary from secondary glioblastomas. For this reason, we evaluated the expression of 340 miRNAs and investigated the crucial role of miR155 in gliomagenesis using 5 high-grade gliomas in primary culture.

\section{Materials and methods}

Human tissue samples. Ninety-three patients with glioblastoma tumours were admitted to our institutions; 66 patients had primary glioblastoma while the remaining 27 had secondary glioblastoma.

Fresh-frozen human glioblastoma samples were obtained for further analysis during surgical procedures and subjected to RNA extraction soon after arrival in the laboratory. All human materials were used in accordance with the policies of local institutional review boards. With written informed consent obtained from all patients, tumour RNA was obtained for molecular analysis. Patients ranged in age from 19-75 years with a mean age of 61 years, with $>80 \%$ of patients being older than 50 years.

Tumours were classified according to the last WHO classification of central nervous tumours (20), and clinical histories recorded. Tumours were diagnosed as primary glioblastoma if at the time of the first surgery a prior history of glioma was not documented, and as secondary glioblastoma if a histological diagnosis of low-grade astrocytoma preceded by at least 1 year the diagnosis of glioblastoma.

Due to the known genotypic differences between oligodendroglial and astrocytic tumours, lesions with histological evidence of a prominent oligodendroglial component were excluded. Moreover, the 'giant cell' variant of glioblastoma was excluded as it has a genetic pattern overlapping that of primary and secondary glioblastoma (23).

For each case, the data including gender, age, location of tumour and survival time were collected and deposited at the Gene Expression Omnibus (GEO) database at the National Centre for Biotechnology Information (NCBI). A data summary is reported in Table I.

Microarray fabrication. Standard microscope glass slides from Sigma were activated with glycidyloxipropyltrimethoxysilane (GOPTS) as previously described (24). These activated epoxy glass slides immobilise amino-modified oligonucleotide DNA.

A 340 custom oligo array, comprising positive and negative control probes, was built where each DNA probe was complementary to a corresponding full length of mature miRNA.
Detailed information on microarray protocols can be found at the GEO database at the NCBI.

miRNA extraction labelling and hybridisation. Total RNA was extracted from tissue using TRIzol ${ }^{\mathrm{TM}}$ (Invitrogen). After pulverizing the tissue in a stainless steel mortar and pestle chilled with liquid nitrogen, miRNA was isolated using a PureLink $^{\mathrm{TM}}$ miRNA Isolation kit (Invitrogen) following the manufacturer's instructions.

The NCode ${ }^{\mathrm{TM}}$ miRNA Labeling System (Invitrogen) was used according to manufacturer's instructions and miRNAs were tagged, hybridised and then placed onto the microarray. After washing, the array was hybridised with Alexa Fluor ${ }^{\circledR} 3$ and AlexaFluor ${ }^{\circledR} 5$ capture reagents. Following further washing, the array was scanned using an Affimetrix 428 array scanner.

Real-time quantitative PCR (RTi-qPCR) and Northern blot analysis. Total RNA was reverse-transcribed to cDNA using primers gene-specific to all of the miRNAs (25). The expression of the miRNA precursors was determined using RTi-qPCR as previously described (26) with several modifications. The master mix contained $0.5 \mathrm{ml}$ of $10 \mathrm{X}$ PCR buffer, $0.7 \mathrm{ml}$ of $25 \mathrm{mM} \mathrm{MgCl}, 0.1 \mathrm{ml}$ of $12.5 \mathrm{mM}$ dNTPs, $0.01 \mathrm{ml} \mathrm{UNG}$, $0.025 \mathrm{ml}$ Amplitaq Gold DNA polymerase, $0.5 \mathrm{ml}$ of diluted cDNA (1:50) and water.

All the PCR reagents were from the SYBR-Green core reagent kit (Applied Biosystems). The expression of each miRNA relative to U6 RNA was determined using the $2^{\Delta \Delta \mathrm{CT}}$ method. Northern blot analyses were carried out with total RNA as previously described (25).

Culture of primary glioblastoma cells and siRNA. Earlypassage (passage 3) cultures from 5 independent human high-grade gliomas were obtained by fresh surgical samples (3 primary GBM and 2 secondary GBM). Three cultures were established from each of the 5 high-grade gliomas, to produce a total of 15 early-passage cultures (passage 3 ). Tumour specimens were minced and suspended in $10 \mathrm{ml}$ of Gey's balanced salt solution in a 50-ml tube. After centrifugation at $50 \mathrm{x} \mathrm{g}$ for $5 \mathrm{~min}$, the supernatant was removed and $10 \mathrm{ml}$ of $0.003 \%$ trypsin (Gibco, Berkeley, CA) in a balanced salt solution was added. Following incubation at $37^{\circ} \mathrm{C}$ for $10 \mathrm{~min}$, the upper $2 \mathrm{ml}$ of the supernatant was discarded and the remaining contents were transferred to a $50 \mathrm{ml}$ flask. An additional $10 \mathrm{ml}$ of $0.003 \%$ trypsin was added and the solution was agitated with a magnetic stirrer for $10 \mathrm{~min}$ at $37^{\circ} \mathrm{C}$. After settling for $1 \mathrm{~min}$, the supernatant was removed and refrigerated. The remaining portion was subjected twice to the same process. The supernatant collected from the 3 trypsinization procedures was filtered through a steel mesh filter (no. 160). The filtered single-cell suspension was centrifuged at $50 \mathrm{x} \mathrm{g}$ for $5 \mathrm{~min}$ and the supernatant was discarded. The cell button was suspended in 5-10 ml of medium. Following a cell count, appropriate dilutions were used to seed culture flasks (27). Cells were transfected according to the method described by Tönges et al, using stearyl-R8 like trasfection reagent (28) (stearyl-R8 was chemically synthesised). The results showed that this novel transfection method yielded performances comparable to cationic liposome-mediated transfection for siRNA, while being less cytotoxic in primary neurons. The 
Table I. A summary of clinical information regarding the patients enrolled in this study.

\begin{tabular}{lc}
\hline Clinical data & Values \\
\hline Glioblastoma & 93 \\
primary glioblastoma & 66 \\
secondary glioblastoma & 27 \\
$\quad$ developed by: & \\
$\quad$ diffuse astrocytoma & 12 \\
$\quad$ anaplastic astrocytoma & 15 \\
Age (years, mean values) & 58.7 \\
primary glioblastoma & 64.3 \\
secondary glioblastoma & 44.9 \\
Male/female ratio & 1.21 \\
Tumour location & \\
sub cortical white matter of the cerebral hemispheres & 93 \\
primary glioblastoma sublocalization & \\
temporal & 10 \\
parietal & 15 \\
frontal & 14 \\
occipital & \\
fronto-temporal & 10 \\
secondary glioblastoma sublocalization & 17 \\
temporal & \\
parietal & \\
frontal & \\
occipital & \\
fronto-temporal & 4.9 \\
primaryival (months, mean values) & 4 \\
secondary glioblastoma & 4 \\
\hline
\end{tabular}

reduced stearyl-octarginine concentration required for efficient transfection is the likely explanation for the low cytotoxic side-effects seen in the primary culture (29).

Cytotoxicity assay. The conversion of 3-(4.5-dimethylthiazol2-yl)-2.5-diphenol tetrazolium bromide (MTT) by cells was used as an indicator of cell numbers as previously described (30). This method measured the reduction of MTT by active mitochondria, which resulted in a colour change measured at a 550-nm wavelength.

Experiments were performed to define the linear range of the assay. A positive correlation was observed up to 50,000 cells per well (data not shown). Increasing the concentration of heat-killed cells per well (killed by incubating at $70^{\circ} \mathrm{C}$ for $15 \mathrm{~min}$ ) caused no significant change in the absorbance. Therefore, this spectrophotometric method was deemed a valid technique for measuring the number of viable cells. All subsequent experiments performed were within the linear range of the assay. The percentage of cell survival was calculated as the absorbance ratio of treated to untreated cells.

\section{Results}

Gene expression profiling. The expression profiles of 340 mammalian miRNAs were analysed by DNA microarrays in 66 primary and 27 secondary glioblastomas and compared with normal adult brains. The latter was from commercially available normal brain tissue (FirstChoice ${ }^{\circledR}$ Total RNA, Applied Biosytems) and normal brain tissue obtained during surgery at our institutions. We selected all miRNAs expressed in at least 20 samples of the same group having a signal value $>100$, thus avoiding low-expression genes. Among them, miRNAs with a signal-to-noise ratio of $>2.5$ were selected for further analysis. Using these parameters, we obtained 86 selected gene features. Using Pearson's correlation co-efficients, average linkage clustering analysis was applied to all tissues, on the basis of the similarity of expression patterns over the 86 selected genes. As expected, this yielded 2 major clusters, one representing the primary glioblastoma group and the other the secondary glioblastoma group (Fig. 1a).

Subsequently, we independently filtered miRNAs showing differential expression between primary or secondary glioblastoma tumour tissue and normal brain tissue by means of ANOVA analysis. Parametric Student's t-test was applied, assuming equal variances, with a p-value cut-off of 0.01 and with multiple testing corrections (Benjamini-Hochberg false discovery rate). Using these restrictions we selected 12 gene features. miR-18b, miR-181c, miR-181a, miR-16, miR-15a and miR-128a where found to be down-regulated while miR-21, miR-155, miR-221, miR-347, miR-9 and miR-138 were found to be up-regulated in most glioblastoma samples. miR-21 and miR-155 were up-regulated in all samples analysed suggesting that these miRNAs are characteristic of glioblastoma.

The miRNAs with statistically significant differences were then grouped according to glioblastoma type (primary or secondary). The parametric Student's t-test was again applied assuming equal variances with a p-value cut-off of 0.01 and with multiple testing corrections (Benjamini-Hochberg false discovery rate). This restriction tested all previously selected genes and identified 10 gene features. Approximately $1.0 \%$ of the identified genes were expected to pass the restriction by chance. Using a standard leave-one-out cross-validation procedure, we found the 10 gene feature signatures to be significantly correlated with glioma subtype $(\mathrm{p}=0.01)$ (Fig. 1b). We determined whether machine-learning classifiers predict subtype in the profiles of glioma tissues. We tested multiple classification methods including classification and regression tree (CART), k-nearest neighbor (k-NN), weighted voting (WV) and support vector machine (SVM).

We were able to distinguish primary from secondary glioblastoma types based solely on these 10 miRNAs gene expression profiles as follows: high levels of miR-221 and low levels of miR-128a, miR-181a and miR-181c (primary glioblastomas); elevated levels of miR-9, miR-138, miR-347 and low levels of miR-15a and miR-16 (secondary glioblastomas, Fig. 1b). miR-21, miR-221, miR-155 were strongly elevated in the primary glioblastoma samples tested, as well as in the 5 early-passage cultures established from 5 patients.

RTi-qPCR. Up- or down-regulated miRNAs were validated by $\mathrm{RTi}-\mathrm{qPCR}$ in 15 randomly chosen primary glioblastoma 

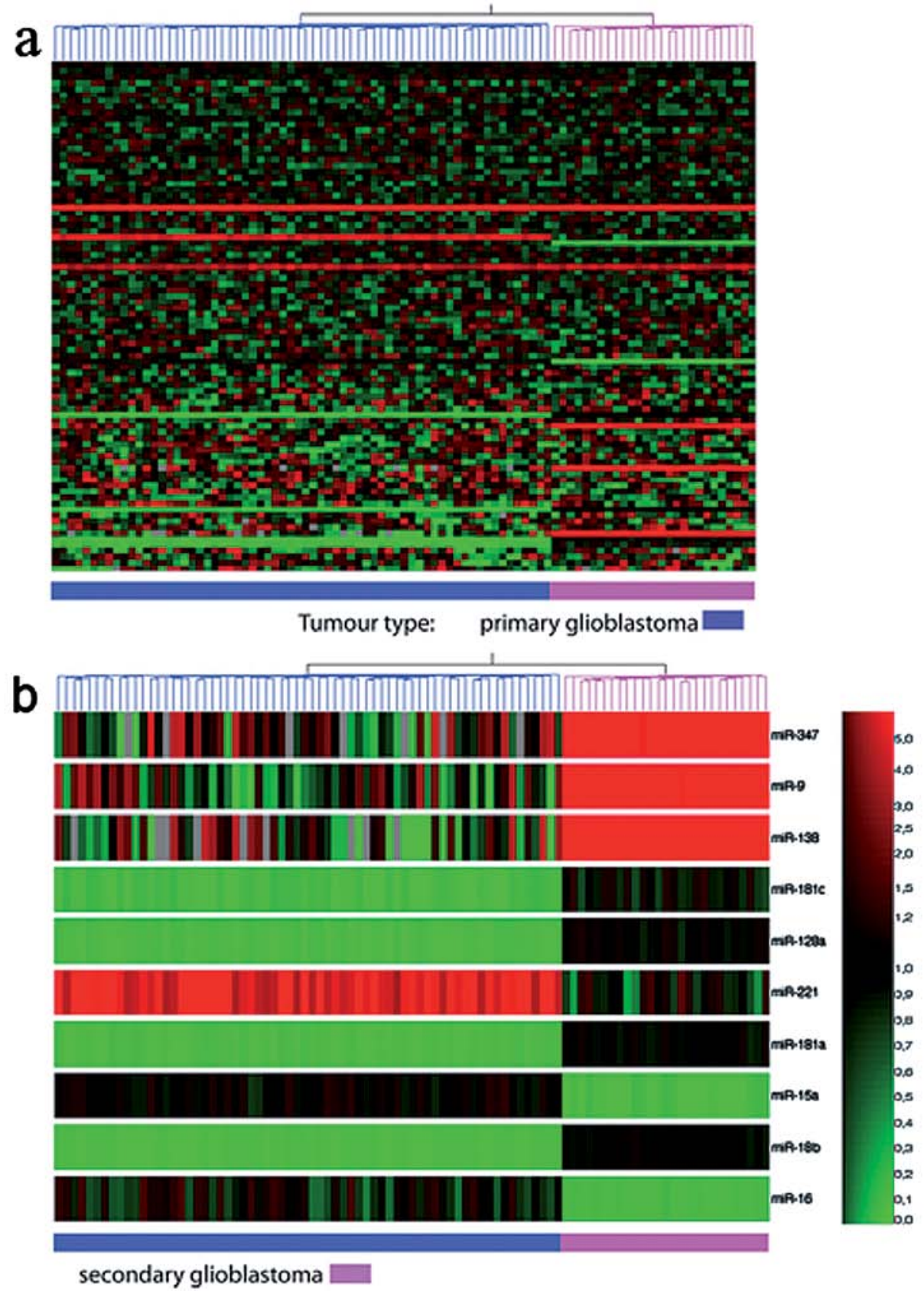

Figure 1. Cluster analysis. (a) The tree generated by a cluster analysis performed on 86 miRNAs showing the separation of primary glioblastoma from secondary glioblastoma tumours. (b) The tree generated by a cluster analysis performed on 10 miRNAs showing a clear separation of primary glioblastoma from secondary glioblastoma tumours.

tissues, and in 15 randomly chosen secondary glioblastoma tissues vs. normal adult brain tissue as the control. We selected a representative cluster of both up- and down-regulated genes in both primary and secondary glioblastoma. In some cases, we obtained a greater difference in respect to the microarray data (Fig. 2). The expression of each miRNA relative to U6 RNA was determined using the $2^{\Delta \Delta \mathrm{Ct}}$ method.

Gene silencing. Previous studies have demonstrated that miR-21 is up-regulated in primary brain tumours and acts as an anti-apoptotic factor in glioblastoma cells (13). In the present study, we demonstrated that in addition to miR-21, miR-155 was also up-regulated in all the glioblastoma tumours analysed. We therefore focused our attention on miR-155 up-regulation.

The targets of miR-155 include the $\gamma$-aminobutyric acid (GABA) A receptor 1 (GABRA1), suppressor of cytokine signaling 1 (SOCS1), adenomatous polyposis coli (APC), and WEE1. We tried to verify whether miR-155 suppression affected its targets by means of RTi-qPCR in primary cultures. One day after miR-155 silencing, no changes were reported in SOCS1, APC and WEE1 expression while an increase in the GABRA1 mRNA level was observed. Labrakakis et al and Betel et al suggested a link between the expression of GABA receptors and the growth of glioma cells, since the loss of GABA receptors parallels the uninhibited growth typical of 


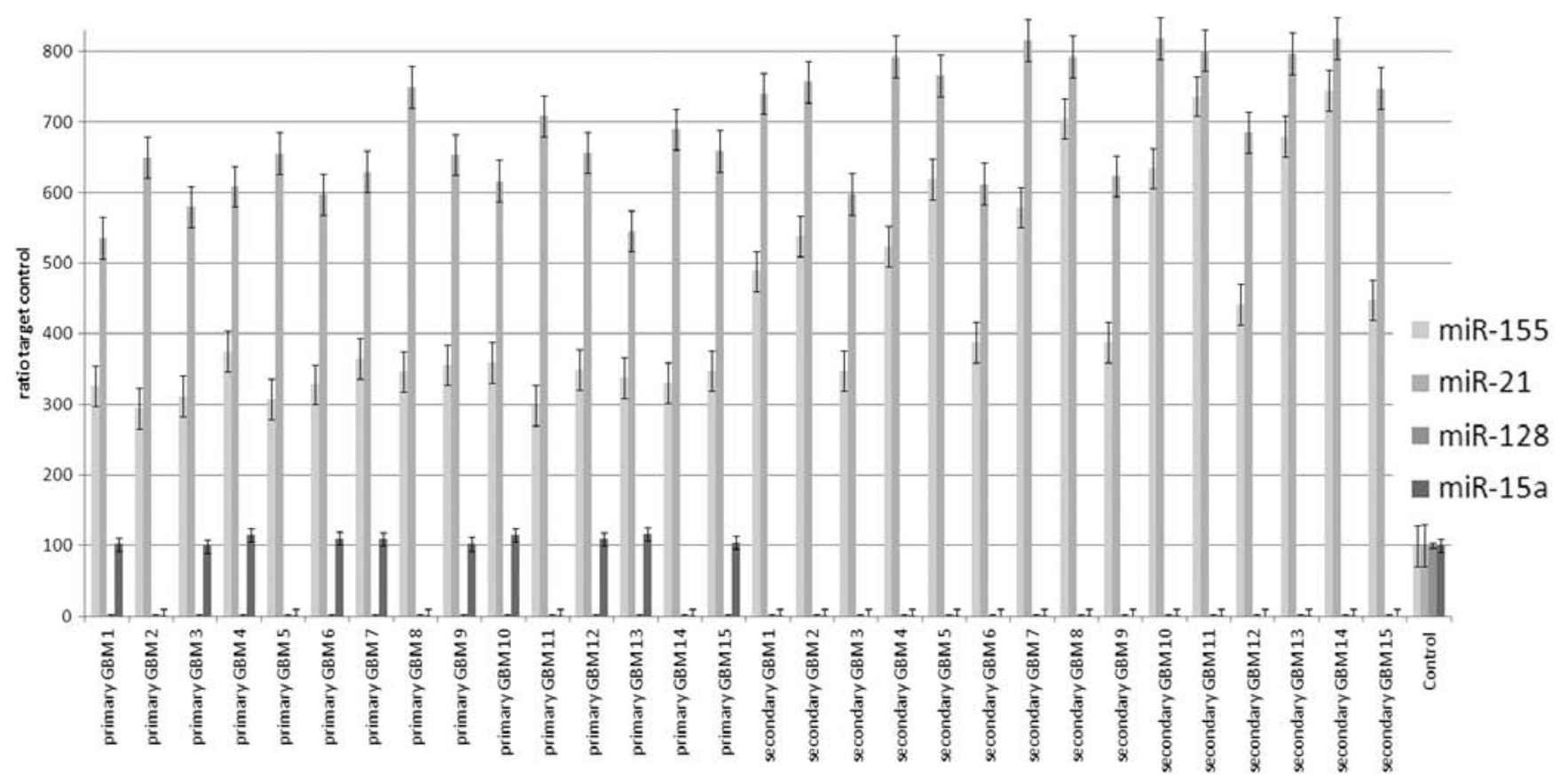

Figure 2. Real-time analysis. Microarray expression data was confirmed by real-time quantitative PCR on miR-155, miR-21, miR-128a and miR-15a. The Pfaffl method was adopted using the U6 gene as the reference gene. The ratio was calculated by the following formula: Ratio $=\left(\mathrm{E}_{\text {target }}\right)^{\Delta \mathrm{Ct} \text { target }(\text { control-test })} /\left(\mathrm{E}_{\text {reference }}\right)^{\Delta \mathrm{Ct} \text { reference }}$ (control-test); (p<0.01). GBM, glioblastoma multiforme.

malignant tumours and immortalised cell lines $(31,32)$. We investigated the correlation between GABRA1 down-regulation and miR-155 up-regulation and their implications on cell proliferation.

Human glioblastoma cells were GABRA1-negative since Northern blot analysis showed no expression of GABRA1 mRNA in glioblastoma primary cultures (Fig. 3a) and, accordingly, immunohistochemical results showed no expression of GABRA1 in paraffin-embedded glioblastoma tissue sections (data not shown). In order to study the biological significance of miR-155 up-regulation and its correlation with GABRA1 expression, we used a loss-of-function approach. A methodology using 2'-O-methyloligoribonucleotides as sequence-specific inhibitors of miRNA function and miRNA-directed RISC activity has previously been reported (33). These molecules stoichiometrically bind and irreversibly inactivate miRNAs, providing a valuable means of disrupting the function of a single miRNA in vitro and in vivo.

In order to test whether miR-155 suppression alters GABRA1 expression, we transfected the 2'-O-methyloligonucleotide complementary to miR-155 into primary cultures and performed Northern blot analysis one day after transfection. The results showed that the miRNA target became undetectable after the introduction of 2'-O-methyloligonucleotide in the low nanomolar range used and that miR-155 suppression resulted in an increase in GABRA1 mRNA expression (Fig. 3). This effect was sequence-specific. miR-155 was blocked by the corresponding antisense 2'-O-methyloligonucleotide (2'OMe-miR-155), but not by an unrelated 2'-O-methyloligonucleotide (2'OMe-EGFP) (Fig. 3b). These results were confirmed using Northern blot analysis for GABRA1 (Fig. 3c). Eight hours after transfection, miR-155-suppressed cells were stimulated with GABA and the cell number was evaluated by MTT assay and plate count. In cells transfected with 2'OMe-miR-155, GABA induced a significant decrease in cell number, whilst no response was observed in cells transfected with 2 'OMe-EGFP (Fig. 4). These results strongly suggest that in glioblastoma cells, the up-regulation of miR-155 may be linked to the down-regulation of GABRA1 and to the loss of the anti-proliferative effects of GABA.

\section{Discussion}

We studied the expression profile of 340 miRNAs by means of a microarray methodology. Using a miRNA expression profiles, we were able to distinguish between primary and secondary glioblastomas, and the up-regulation of both miR-21 and miR-155 were clear indicators of the tumoural state.

Starting with expression data relating to all genes studied, we selected those having a significant difference between primary and secondary glioblastomas. When cluster analysis was performed using the expression of only these genes, we were able to divide glioblastoma tumours in two subclasses coinciding with neuroradiological and histological primary and secondary glioblastoma.

miR-21 was up-regulated in primary and secondary glioblastoma and in all the cell lines tested. We confirmed the array-identified up-regulation of miR-21 by RTi-qPCR, obtaining a greater difference with respect to the microarray data. miR-21 expression was increased from 10 to 100 -fold in glioblastoma tissue compared with control non-neoplastic brain tissue.

Previous studies have shown that primary brain tumours, such as anaplastic astrocytoma, oligoastrocytoma, oligo- 


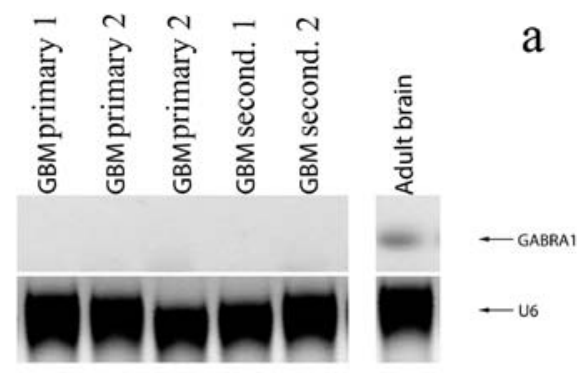

b
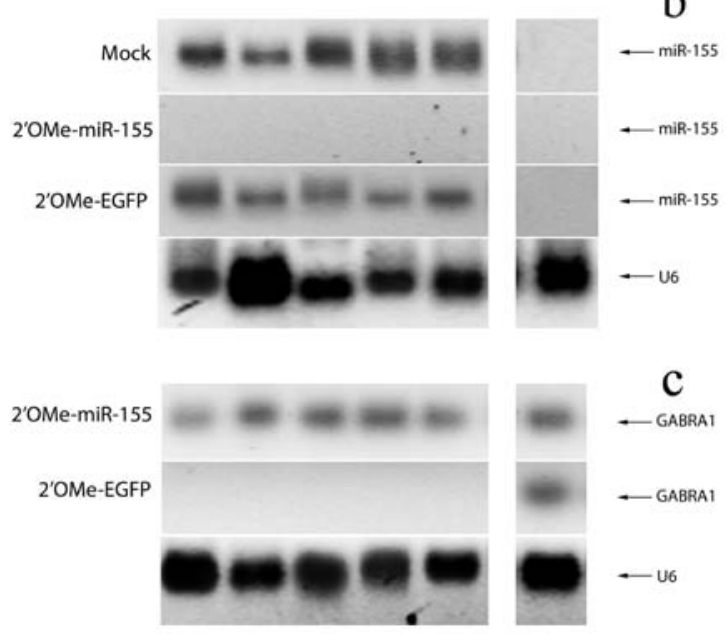

Figure 3. Northern blot analysis. (a) Northern blot analysis showing GABRA1 expression. The same blot was re-probed with U6 as the loading control. (b) Northern blot analysis showing the expression of miR-155 after transfection with the vehicle control (mock), with a 2'-O-methyloligonucleotide complementary to miR-155 (2'OMe-miR-155) and an irrelevant 2'-O-methyloligonucleotide (2'OMe-EGFP). The same blot was re-probed with U6 as the loading control. (c) Northern blot analysis showing the expression of GABRA1 after trasfection with a 2'-O-methyloligonucleotide complementary to miR-155 (2'OMe-miR-155) and an irrelevant 2'-O-methyloligonucleotide (2'OMe-EGFP). The same blot was re-probed with U6 as the loading control (each blot was re-probed with the U6 probe but only one blot of U6 for each treatment is shown). GBM, glioblastoma multiforme; GABRA1, $\gamma$-aminobutyric acid A receptor.

dendroglioma and medulloblastoma are characterised by an increase in miR-21 expression; however, very high levels of this miRNA are more typical of glioblastomas (18,34-38).

Moreover, it has been demonstrated that miR-21 acts as an anti-apoptotic factor in glioblastoma cells, suggesting that the aberrantly increased expression of miR-21 may down-regulate the translation or stability of mRNA(s) coding for apoptosisrelated genes, although the precise targets of miR-21 remains elusive (18).

It can be postulated that the aberrant increased expression of this miRNA may block the expression of gene products that promote normal glial differentiation or that induce apoptosis, holding tumour cells in an inappropriately primitive and proliferative developmental state.

miR-155 potential targets include the tumour suppressor genes, SOCS1 and APC, and the kinase WEE1, which blocks the activity of $\mathrm{Cdc} 2$ and prevents entry into mitosis. The hypoxiainducible factor (HIF)1A is also a predicted target. Interestingly, among predicted genes, the tripartite motif-containing protein 2 (TRIM2), the proto-oncogene, sphingosine kinase 1 (SKI), and the RAS homologues, RAB6A and RAB6C, were found as potential targets of both miR-21 and miR-155 (32).

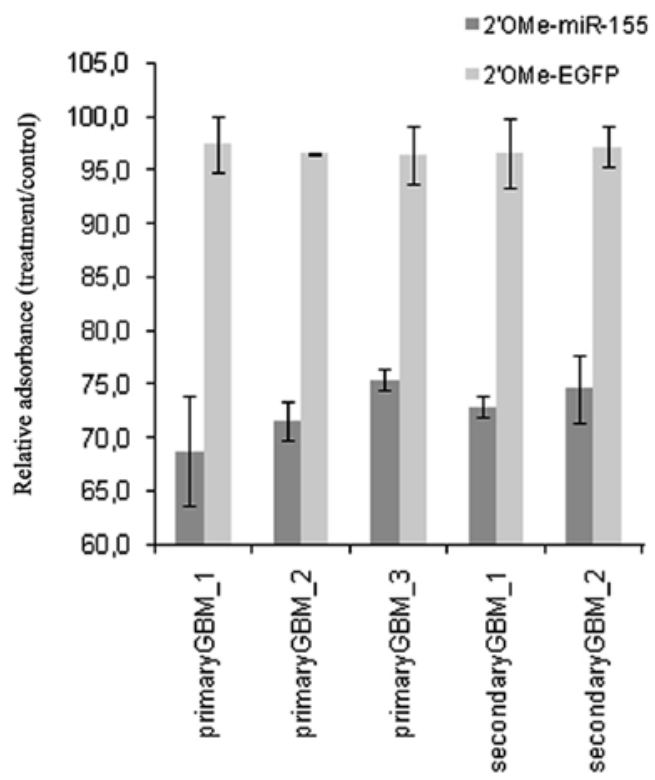

Figure 4. The sensitivity of the cells to $\gamma$-aminobutyric acid (GABA) stimulation. Cells were transfected with a 2'-O-methyloligonucleotide complementary to miR-155 (2'OMe-miR-155) and an irrelevant 2'-O-methyloligonucleotide (2'OMe-EGFP). The data represent the means \pm SD from 4 different experiments with 8 replicate wells in each microtitre plate $(p<0.01)$. GBM, glioblastoma multiforme.

One of the miR-155 targets is GABRA (31). Labrakakis et al suggested a link between the expression of GABA receptors and the growth of glioma cells since the disappearance of functional GABA receptor parallels the uninhibited growth typical of malignant tumours and immortal cell lines (32).

We studied the correlation between GABRA1 downregulation and miR-155 up-regulation, and the implications for cell proliferation control. Our data suggest that in glioblastoma cells one of the effects of miR-155 up-regulation may be the down-regulation of GABRA1, which renders tumour cells unresponsive to GABA cell proliferation inhibition, playing an important role in the chain of events that induce uninhibited cellular growth in malignant tumours.

In conclusion, although a different pattern of miRNA expression characterises primary and secondary glioblastoma, these tumours have the common up-regulation of both miR-21 and miR-155, which hold tumour cells in an inappropriately primitive and proliferative developmental state.

\section{References}

1. Bartel DP: MicroRNAs: genomics, biogenesis, mechanism, and function. Cell 116: 281-297, 2004.

2. Sempere LF, Freemantle S, Pitha-Rowe I, Moss E, Dmitrovsky E and Ambros V: Expression profiling of mammalian microRNAs uncovers a subset of brain-expressed microRNAs with possible roles in murine and human neuronal differentiation. Genome Biol 5: R13, 2004

3. Malzkorn B, Wolter M, Liesenberg F, Grzendowski M, Stuhler K, Meyer HE and Reifenberger G: Identification and functional characterization of microRNAs involved in the malignat progression of gliomas. Brain Pathol 20: 539-550, 2010.

4. Miska EA, Alvarez-Saavedra E, Townsend M, Yoshii A, Sestan N, Rakic P, Constantine-Paton M and Horvitz HR: Microarray analysis of microRNA expression in the developing mammalian brain. Genome Biol 5: R68, 2004. 
5. Calin GA, Sevignani C, Dumitru CD, Hyslop T, Noch E, Yendamuri S, Shimizu M, Rattan S, Bullrich F, Negrini M and Croce CM: Human microRNA genes are frequently located at fragile sites and genomic regions involved in cancers. Proc Natl Acad Sci USA 101: 2999-3004, 2004.

6. Calin GA, Liu CG, Sevignani C, Ferracin M, Felli N, Dumitru CD, Shimizu M, Cimmino A, Zupo S, Dono M, Dell'Aquila ML, Alder H, Rassenti L, Kipps TJ, Bullrich F, Negrini M and Croce CM: MicroRNA profiling reveals distinct signatures in $\mathrm{B}$ cell chronic lymphocytic leukemias. Proc Natl Acad Sci USA 101: 11755-11760, 2004.

7. Eis PS, Tam W, Sun L, Chadburn A, Li Z, Gomez MF, Lund E and Dahlberg JE: Accumulation of miR-155 and BIC RNA in human B cell lymphomas. Proc Natl Acad Sci USA 102 3627-3632, 2005.

8. Johnson SM, Grosshans H, Shingara J, Byrom M, Jarvis R, Cheng A, Labourier E, Reinert KL, Brown D and Slack FJ: RAS is regulated by the let-7 microRNA family. Cell 120: 635-647, 2005.

9. Lu J, Getz G, Miska EA, Alvarez-Saavedra E, Lamb J, Peck D, Sweet-Cordero A, Ebert BL, Mak RH, Ferrando AA, Downing JR, Jacks T, Horvitz HR and Golub TR: MicroRNA expression profiles classify human cancers. Nature 435: 834-838, 2005.

10. He L, Thomson JM, Hemann MT, Hernando-Monge E, Mu D, Goodson S, Powers S, Cordon-Cardo C, Lowe SW, Hannon GJ and Hammond SM: A microRNA polycistron as a potential human oncogene. Nature 435: 828-833, 2005.

11. O'Donnell KA, Wentzel EA, Zeller KI, Dang CV and Mendell JT: c-Myc-regulated microRNAs modulate E2F1 expression. Nature 435: 839-843, 2005

12. Costinean S, Zanesi N, Pekarsky Y, Tili E, Volinia S, Heerema $\mathrm{N}$ and Croce CM: Pre-B cell proliferation and lymphoblastic leukemia/high-grade lymphoma in $\mathrm{E}(\mathrm{mu})$ miR155 transgenic mice. Proc Natl Acad Sci USA 103: 7024-7029, 2006

13. Kluiver J, Poppema S, de Jong D, Blokzijl T, Harms G, Jacobs S, Kroesen BJ, and van den Berg A: BIC and miR-155 are highly expressed in Hodgkin, primary mediastinal and diffuse large B cell lymphomas. J Pathol 207: 243-249, 2005.

14. van den Berg A, Kroesen BJ, Kooistra K, de Jong D, Briggs J, Blokzijl T, Jacobs S, Kluiver J, Diepstra A, Maggio E and Poppema S: High expression of B-cell receptor inducible gene BIC in all subtypes of Hodgkin lymphoma. Genes Chromosomes Cancer 37: 20-28, 2003

15. Volinia S, Calin GA, Liu CG, Ambs S, Cimmino A, Petrocca F, Visone R, Iorio M, Roldo C, Ferracin M, Prueitt RL, Yanaihara N, Lanza G, Scarpa A, Vecchione A, Negrini M, Harris CC and Croce CM: A microRNA expression signature of human solid tumors defines cancer gene targets. Proc Natl Acad Sci USA 103 2257-2261, 2006

16. Tam W, Hughes SH, Hayward WS and Besmer P: Avian bic, a gene isolated from a common retroviral site in avian leukosis virus-induced lymphomas that encodes a noncoding RNA, cooperates with c-myc in lymphomagenesis and erythroleukemogenesis. J Virol 76: 4275-4286, 2002.

17. Yanaihara N, Caplen N, Bowman E, Seike M, Kumamoto K, Yi M, Stephens RM, Okamoto A, Yokota J, Tanaka T, Calin GA, Liu CG, Croce CM and Harris CC: Unique microRNA molecular profiles in lung cancer diagnosis and prognosis. Cancer Cell 9: $189-198,2006$

18. Chan JA, Krichevsky AM and Kosik KS: MicroRNA-21 is an antiapoptotic factor in human glioblastoma cells. Cancer Res 65: 6029-6033, 2005.

19. Huse JT, Brennan C, Hambardzumyan D, Wee B, Pena J, Rouhanifard SH, Sohn-Lee C, le Sage C, Agami R, Tuschl T and Holland EC: The PTEN-regulating microRNA miR-26a is amplified in high-grade glioma and facilitates gliomagenesis in vivo. Genes Dev 23: 1327-1337, 2009.
20. Louis DN, Ohgaki H, Wiestler OD, Cavenee WK, Burger PC, Jouvet A, Scheithauer BW and Kleihues P: The 2007 WHO classification of tumours of the central nervous system. Acta Neuropathol 114: 97-109, 2007

21. Tso CL, Freije WA, Day A, Chen Z, Merriman B, Perlina A, Lee Y, Dia EQ, Yoshimoto K, Mischel PS, Liau LM, Cloughesy TF and Nelson SF: Distinct transcription profiles of primary and secondary glioblastoma subgroups. Cancer Res 66: 159-167, 2006.

22. Kleihues $\mathrm{P}$ and Ohgaki H: Primary and secondary glioblastomas: from concept to clinical diagnosis. Neuro Oncol 1: 44-51, 1999.

23. Schmidt MC, Antweiler S, Urban N, Mueller W, Kuklik A, Meyer-Puttlitz B, Wiestler OD, Louis DN, Fimmers R and von Deimling A: Impact of genotype and morphology on the prognosis of glioblastoma. J Neuropathol Exp Neurol 61: 321-328, 2002.

24. Liang RQ, Tan CY and Ruan KC: Colorimetric detection of protein microarrays based on nanogold probe coupled with silver enhancement. J Immunol Methods 285: 157-163, 2004.

25. Schmittgen TD, Jiang J, Liu Q and Yang L: A high-throughput method to monitor the expression of microRNA precursors. Nucleic Acids Res 32: e43, 2004.

26. Krichevsky AM, King KS, Donahue CP, Khrapko K and Kosik KS: A microRNA array reveals extensive regulation of microRNAs during brain development. RNA 9: 1274-1281, 2003.

27. Barker M, Wilson CB and I-Ioshino T: Tissue culture of human brain tumors. In: The Experimental Biology of Brain Tumors. Kirsch WM, Paletti EG and Paotetti P (eds). Thomas, Springfield, IL, pp57-84, 1972.

28. Tönges L, Lingor P, Egle R, Dietz GP, Fahr A and Bähr M: Stearylated octaarginine and artificial virus-like particles for transfection of siRNA into primary rat neurons RNA 12: 1431-1438, 2006.

29. Lingor P, Michel U, Scholl U, Bahr M and Kugler S: Transfection of 'naked' siRNA results in endosomal uptake and metabolic impairment in cultured neurons. Biochem Biophys Res Commun 315: 1126-1133, 2004.

30. Muscella A, Greco S, Elia MG, Storelli C and Marsigliante S: Angiotensin II stimulation of $\mathrm{Na}^{+} / \mathrm{K}^{+}$ATPase activity and cell grow th by calcium-independent pathway in MCF-7 breast cancer cells. J Endocrinol 173: 315-323, 2002.

31. Betel D, Wilson M, Gabow A, Marks DS and Sander C: The microRNA.org resource: targets and expression. Nucleic Acids Res 36 (database issue): D149-D153, 2008.

32. Labrakakis C, Patt S, Hartmann J and Kettenmann H: Functional GABA(A) receptors on human glioma cells. Eur J Neurosi 10: 231-238, 1998.

33. Meister G, Landthaler M, Dorsett Y and Tuschl T: Sequencespecific inhibition of microRNA- and siRNAinduced RNA silencing. RNA 10: 544-550, 2004

34. Chiocca EA and Lawler SE: The many functions of microRNAs in glioblastoma. World Neurosurg 73: 598-601, 2010.

35. Lawler S and Chiocca EA: Emerging functions of microRNAs in glioblastoma. J Neurooncol 92: 297-306, 2009.

36. Corsten MF, Miranda R, Kasmieh R, Krichevsky AM, Weissleder R and Shah K: MicroRNA-21 knockdown disrupts glioma gtowth in vivo and displays synergistic cytotoxicity with neural precursor cell delivered S-TRAIL in human glioma. Cancer Res 67: 8994-9000, 2007.

37. Gabriely G, Wurdinger T, Kesari S, Esau CC, Burchard J, Linsley PS and Krichevsky AM: MicroRNA 21 promotes glioma invasion by targeting matrix metalloproteinase regulators. Mol Cell Biol 28: 5369-5380, 2008 .

38. Conti A, Aguennouz MH, La Torre D, Tomasello C, Cardali S, Angileri FF, Maio F, Cama A, Germano A, Vita G and Tomasello F: miR-21 and 221 upregulation and miR-181b downregulation in human grade II-IV astrocytic tumors. J Neurooncol 93: 325-332, 2009. 